\title{
USE OF A SUPERSPREADER ADJUVANT TO REDUCE SPRAY APPLICATION VOLUMES ON AVOCADOS
}

\author{
R.E. GASKIN ${ }^{1}$, D.W.L. MANKTELOW ${ }^{2}$, S.J. SKINNER ${ }^{1}$ \\ and G.S. ELLIOTT ${ }^{3}$ \\ ${ }^{1} P P C_{N Z}$, Forest Research, Private Bag 3020, Rotorua \\ ${ }^{2}$ HortResearch, Private Bag 1401, Havelock North \\ ${ }^{3}$ Elliott Chemicals Ltd, P O Box 18-417, Glen Innes, Auckland
}

Corresponding author: robyn.gaskin@forestresearch.co.nz

\begin{abstract}
This study was undertaken to determine whether pesticide spray volumes on avocados could be substantially lowered with the use of a superspreader adjuvant, and to identify an optimum spray volume and adjuvant rate to maximise spray retention. Ground-based airblast applications of copper fungicide were made to 4-5 year old fruit-bearing trees. Spray retention was quantified on foliage and fruit, at a range of canopy heights and positions. Spray deposits on foliage were maintained or improved using reduced volume sprays (500-700 litres/ha) incorporating the superspreader Du-Wett, compared to the standard high volume treatment (2500 litres/ ha). The adjuvant maintained total spray deposits on fruit using 3-5 times less spray volume than is current standard practice. There was no evidence of phytotoxicity on any fruit or foliage due to adjuvant sprays. The study highlighted deficiencies in current spray application technology used on avocados.
\end{abstract}

Keywords: spray retention, organosilicone adjuvant, pesticide sprays, application technology.

\section{INTRODUCTION}

The use of super-spreader organosilicone adjuvants has allowed growers to reduce pesticide spray volumes and improve pest and disease control in a variety of crops, e.g. onions, potatoes, kiwifruit and grapes (Gaskin et al 2002). Avocado growers face particular challenges when it comes to achieving coverage on very large trees and may apply sprays from the ground or by helicopter. Ground-based technology generally involves the application of high volumes (up to 5000 litres/ha) to achieve coverage of pesticide sprays. High volumes represent high application costs, low work rates, potential losses through drift and run-off, and reduced operational flexibility. However, growers do not consider spraying avocados with low volume sprays because experience has taught them that it compromises efficacy.

Few growers use adjuvants in their spray programmes due to anecdotal evidence suggesting avocado trees are highly susceptible to damage by spray adjuvants. A recent study (Hofstee \& Gaskin 2003) has shown that two superspreader adjuvants developed specifically for horticultural use can be used on avocado trees without any adverse effects on fruit. However, there is a risk of damaging foliage with inappropriately high combinations of adjuvant concentration and spray volume.

This study was undertaken to (1) determine whether spray volumes could be substantially reduced without compromising spray coverage on leaves and fruit, and (2) identify a non-phytotoxic adjuvant concentration and spray volume combination for ground-based fungicide sprays to maximise spray retention on dense-canopied, young avocado trees. 


\section{MATERIALS AND METHODS}

Hass avocado trees in a commercial orchard near Te Puke were randomly allocated to four treatments. Trees were 5 years old, ca $4.5 \mathrm{~m}$ tall, and carrying dense foliage and good numbers of fruit at the time of the trial in July 2003. They were planted at $7 \mathrm{~m}$ row spacing. Some minor frost damage was evident on most trees. Each plot comprised five trees in the shape of a cross. Spraying was done from only one side of the sprayer. Firstly, three trees in a row were sprayed on both sides. The sprayer was then turned 90 degrees and sprayed another line of three trees on both sides. The plot was centred on a central sample tree, which was treated from four sides in line with normal spray application practice on this orchard. Buffers of at least one row of trees existed between each treatment. All treatments were applied on the same day. Wind speeds were $<1 \mathrm{~m} / \mathrm{sec}$, temperatures were in the range $14-17^{\circ} \mathrm{C}$ and $\mathrm{RH}$ was $>70 \%$. Copper (Kocide $2000 \mathrm{LF)} \mathrm{was} \mathrm{applied} \mathrm{at} \mathrm{a} \mathrm{standard} \mathrm{application} \mathrm{rate}$ $(3.4 \mathrm{~kg} / \mathrm{ha})$. The control treatment was applied in 2500 litres/ha without adjuvant. There were three treatments containing a horticultural superspreader $\left(\mathrm{Du}-\mathrm{Wett}^{\circledR}\right.$, Elliott $^{\circledR}$ Chemicals Ltd.). These were applied as reduced spray volumes of 700 litres/ha (plus $200 \mathrm{ml} /$ ha adjuvant) or 500 litres/ha (plus 200 or $400 \mathrm{ml} /$ ha adjuvant) (Table 1). There were two replicates of all treatments within a completely randomised design. All treatments contained tartrazine food dye at $5 \mathrm{~g} / \mathrm{litre}$.

The sprayer was a Pearce 2000 airblast fitted with an $820 \mathrm{~mm}$ diameter axial fan with no straightening vanes. For normal spraying work on the orchard, the sprayer was run at $480 \mathrm{rpm}$ at the PTO to produce an average air speed of $29 \mathrm{~m} / \mathrm{s}$ at the nozzles or ca $31,000 \mathrm{~m}^{3} / \mathrm{h}$. A typical travel speed for treating this avocado block, measured at $2.5 \mathrm{~km} / \mathrm{h}$, was used in the experiment. The air output from the sprayer was considered adequate to achieve coverage in the tops of the trees at the relatively slow travel speed. All treatments were delivered using Tee Jet TX hollow cone nozzles (2500 litres/ha = 18,26, 26, 18, $12 @ 2400 \mathrm{kPa}, 700$ litres/ha=10, 12, 12,10, 8 @ $750 \mathrm{kPa}$ and 500 litres/ ha =6, 8, 8, 6, $4 @ 980 \mathrm{kPa}$ ). These nozzle selections all allowed 70\% of the output to be directed into the top half of the target trees. Only five nozzle positions of the seven on the spray ring were used as the very top and bottom positions did not adequately direct output to the target canopy. Individual nozzle outputs were measured and confirmed against expected outputs at the operating pressure. High volume applications in avocados would normally be delivered using disk and core or gun nozzles, which would be expected to produce coarser droplets than these nozzle setups, with greater runoff losses and less even coverage potential.

Samples were collected from the central sample tree immediately after spraying and stored in sealed plastic bags in a cool store until washed the following day. Leaves were sampled from inner and outer canopy positions at three canopy heights: lower $(<1.5 \mathrm{~m})$, mid (1.5-3 m) and upper ( $>3 \mathrm{~m})$. Each sample consisted of six leaves. Two samples were taken from each canopy position, one from each side of the tree (east \& west). Fruit (three per sample) were picked from inner and outer positions at two canopy heights, upper $(>2 \mathrm{~m})$ and lower $(<2 \mathrm{~m})$, on each tree.

Foliage and fruit samples were washed in known aliquots of distilled water $(400 \mathrm{ml})$. The washings were filtered through AP25 pre-filters (Millipore, USA) and dye absorbance was determined as described previously (Murray et al. 1998) to quantify spray recovery. Leaf areas were measured with a Li-Cor 3100 Leaf Area Meter after washing and fruit were weighed fresh in the sample bag prior to washing.

Spray retention results were normalised at $1 \mathrm{~kg} / \mathrm{ha}$ dye application to enable comparison of treatments. Analysis of variance and least significant difference test (LSD) at $\mathrm{P}=0.05$ were used to compare treatment means in a split plot design. Examinations of treated trees were made 4 and 12 weeks after treatment, to determine any signs of phytotoxicity on fruit or foliage. 


\section{RESULTS AND DISCUSSION}

\section{Leaf deposits}

Treatment had a significant effect on spray retention $(\mathrm{P}<0.001)$. The 700 litres/ha+adjuvant treatment was retained significantly more than any other treatment, including the high volume control (Table 1). Lowering the volume of adjuvant sprays from 700 to 500 litres/ha decreased foliar retention on trees of this size and density, although retention on the 500 litres/ha+adjuvant treatments was still similar to the high volume control. Increasing the adjuvant rate tended $(\mathrm{P}>0.05)$ to reduce spray retained on leaves. A reduction in spray retention with increasing adjuvant rate can be attributed to adjuvantinduced loss to runoff. This highlights the need to match adjuvant rates to application volumes on different spraying targets.

The effect of canopy height on spray retention was significant $(\mathrm{P}<0.001)$, indicating the mid canopy foliage retained significantly more spray than upper and lower positions (Table 1). This suggests that an alternative nozzle output arrangement might have improved overall evenness of deposits with height in the trees. However, the variability of deposits with tree height was typical of that observed in tree crop spraying (Manktelow et al. 2004). The deposit data suggests that 700 litres/ha is a good volume for the adjuvant sprays to target the mid and lower canopy in dense, medium sized avocado trees, and that increasing Du-Wett rate reduces retention on the upper canopy.

The outer canopy retained significantly more spray in all treatments $(\mathrm{P}<0.001)$, which is again typical of the variability seen when spraying densely foliated tree crops. Increasing adjuvant concentration and reducing spray volume decreased retention on the outer canopy $(\mathrm{P}<0.05)$, but had no effect on retention by the inner. The 700 litres/ha+adjuvant treatment deposited significantly more spray on the outer canopy than any other treatment. All low volume+adjuvant treatments provided spray deposits equal to the high volume control on the inner canopy.

Fruit deposits

TABLE 1: Retention of sprays (normalised for $1 \mathrm{~kg} \mathrm{dye} / \mathrm{ha}$ ) on avocado foliage with varying adjuvant rates and spray volumes.

\begin{tabular}{cccccc}
\hline & & & \multicolumn{3}{c}{ Retention $\left(\mu \mathrm{g} / \mathrm{cm}^{2}\right)$} \\
\cline { 4 - 6 } $\begin{array}{c}\text { Spray volume } \\
\text { (litres/ha) }\end{array}$ & $\begin{array}{c}\text { Adjuvant in } \\
\text { ml/ha }(\% \text { v/v) }\end{array}$ & $\begin{array}{c}\text { Canopy } \\
\text { position (height) }\end{array}$ & $\begin{array}{c}\text { Inner } \\
\text { canopy }\end{array}$ & $\begin{array}{c}\text { Outer } \\
\text { canopy }\end{array}$ & Mean \\
\hline 2500 & 0 & lower & 1.09 & 2.06 & 1.58 \\
2500 & 0 & mid & 1.35 & 2.37 & 1.86 \\
2500 & 0 & upper & 0.83 & 2.04 & 1.43 \\
Mean & & & $\mathbf{1 . 0 9}$ & $\mathbf{2 . 1 6}$ & $\mathbf{1 . 6 2}$ \\
\hline 700 & $200(0.03)$ & lower & 1.27 & 2.14 & 1.71 \\
700 & $200(0.03)$ & mid & 1.57 & 3.11 & 2.34 \\
700 & $200(0.03)$ & upper & 0.52 & 2.43 & 1.47 \\
Mean & & & $\mathbf{1 . 1 2}$ & $\mathbf{2 . 5 6}$ & $\mathbf{1 . 8 4}$ \\
\hline 500 & $200(0.04)$ & lower & 0.98 & 1.61 & 1.29 \\
500 & $200(0.04)$ & mid & 1.07 & 2.48 & 1.77 \\
500 & $200(0.04)$ & upper & 1.38 & 2.10 & 1.74 \\
Mean & & & $\mathbf{1 . 1 4}$ & $\mathbf{2 . 0 6}$ & $\mathbf{1 . 6 0}$ \\
\hline 500 & $400(0.08)$ & lower & 1.15 & 1.66 & 1.40 \\
500 & $400(0.08)$ & mid & 1.32 & 1.89 & 1.60 \\
500 & $400(0.08)$ & upper & 1.07 & 1.69 & 1.38 \\
Mean & & & $\mathbf{1 . 1 8}$ & $\mathbf{1 . 7 5}$ & $\mathbf{1 . 4 6}$ \\
LSD (P<0.05) for comparing the four treatment means & NSD & 0.25 & 0.18 \\
\hline
\end{tabular}

${ }^{1} \mathrm{NSD}=$ No significant difference between the four treatment means. 
There were no treatment differences for fruit deposits, with all low volume+adjuvant sprays retained on fruit similarly to the high volume control (Table 2). The trend was for increasing Du-Wett concentration to reduce spray retained, but this was not significant.

As with foliage, there was a significant effect of canopy height on fruit deposits $(\mathrm{P}<0.001)$. In all treatments, fruit in the lower canopy retained at least twice as much total spray as those in the upper canopy (Table 2). There were no differences between treatments in retention on upper canopy fruit. In the lower canopy, the 500 litres/ha+low rate adjuvant retained less spray $(\mathrm{P}<0.05)$ than the high volume control, but the total results suggest redistribution of spray (more on the upper canopy) rather than loss. The outer canopy fruit retained significantly more spray in all treatments $(\mathrm{P}<0.001)$. There were no differences between treatments within the inner and outer fruit positions (Table 2), although retention data on the outer fruit in the upper canopy suggests increasing $\mathrm{Du}$-Wett concentration may increase runoff.

The distribution and spread of spray droplets were not quantified in this experiment. However, visual examination of fruit and leaves indicated that the low volume+adjuvant applications provided excellent and even spray droplet coverage across leaf and fruit surfaces with runoff only observed on the outer canopy in close proximity to the sprayer.

TABLE 2: Retention of sprays (normalised for $1 \mathrm{~kg}$ dye/ha) on avocado fruit with varying adjuvant rates and spray volumes.

\begin{tabular}{|c|c|c|c|c|c|}
\hline \multirow[b]{2}{*}{$\begin{array}{l}\text { Spray volume } \\
\text { (litres/ha) }\end{array}$} & \multirow[b]{2}{*}{$\begin{array}{l}\text { Adjuvant in } \\
\mathrm{ml} / \mathrm{ha}(\% \mathrm{v} / \mathrm{v})\end{array}$} & \multirow[b]{2}{*}{$\begin{array}{c}\text { Canopy } \\
\text { position (height) }\end{array}$} & \multicolumn{3}{|c|}{ Retention $\left(\mu \mathrm{g} / \mathrm{cm}^{2}\right)$} \\
\hline & & & $\begin{array}{l}\text { Inner } \\
\text { canopy }\end{array}$ & $\begin{array}{l}\text { Outer } \\
\text { canopy }\end{array}$ & Mean \\
\hline 2500 & 0 & lower & 1.06 & 1.64 & 1.39 \\
\hline 2500 & 0 & upper & 0.43 & 0.76 & 0.59 \\
\hline Mean & & & 0.70 & 1.20 & 0.97 \\
\hline 700 & $200(0.03)$ & lower & 0.74 & 1.87 & 1.30 \\
\hline 700 & $200(0.03)$ & upper & 0.39 & 0.85 & 0.62 \\
\hline Mean & & & 0.57 & 1.36 & 0.96 \\
\hline 500 & $200(0.04)$ & lower & 0.75 & 1.52 & 1.14 \\
\hline 500 & $200(0.04)$ & upper & 0.47 & 0.97 & 0.72 \\
\hline Mean & & & 0.61 & 1.24 & 0.93 \\
\hline 500 & $400(0.08)$ & lower & 0.99 & 1.56 & 1.28 \\
\hline 500 & $400(0.08)$ & upper & 0.26 & 0.71 & 0.48 \\
\hline \multicolumn{3}{|l|}{ Mean } & 0.62 & 1.13 & 0.88 \\
\hline \multicolumn{3}{|c|}{ LSD $(\mathrm{P}<0.05)$ for comparing the four treatment means } & $\mathrm{NSD}^{1}$ & NSD & NSD \\
\hline
\end{tabular}

${ }^{1} \mathrm{NSD}=$ No significant difference between the four treatment means.

\section{Phytotoxicity}

There was no evidence of spray damage on fruit or foliage up to 12 weeks after spraying, confirming the previous results from full season copper+superspreader adjuvant applications to avocados (Hofstee \& Gaskin 2003).

\section{Sprayer effects}

Retention on inner canopy foliage and fruit was poor relative to the outer canopy; deposits on inner canopy ranged from $42-67 \%$ of those on the outer (Tables $1 \& 2$ ). This is typical of inner versus outer canopy deposit ratios for most tree crops (Manktelow et al. 2004). Spray deposits on upper and lower foliage were always inferior to the middle canopy, with upper generally the most poorly targeted. Upper canopy fruit deposits were only $38-63 \%$ of those on lower fruit. These results were again typical of the variations 
seen in tree crops (Manktelow et al. 2004) and highlight deficiencies in current axial fan airblast spray application technology used on avocados.

Spraying trees in four passes from both row directions requires half the sprayer output volume that would be used to apply the same total application volume from an up and back pass in one row orientation. The absence of any sort of flow meter and the general design of the filtration system, regulators, agitation system, etc., on this type of sprayer means that it is debatable as to whether growers could reliably achieve and maintain these low output volumes without some adaptation to the airblast-type sprayers used typically. In addition, most sprayer operators have little appreciation of how much air their sprayer produces and seldom make any substantive attempts to optimise air outputs for different canopies or spraying conditions.

\section{CONCLUSIONS}

Compared to the standard high volume treatment, spray deposits on foliage could be improved by using reduced volume sprays that incorporate the superspreader adjuvant. The 700 litres/ha spray volume increased total deposits, specifically on foliage comprising the outer and mid-section of the tree. The use of Du-Wett achieved equivalent spray deposits on avocado fruit using 3-5 times less spray volume than is current standard practice. Refining superspreader rates and spray application volumes may well provide improved control of pests and diseases on this crop. The study also highlighted deficiencies in current spray application technology used on avocados. Upper, lower and inner canopies were not well targeted by the airblast sprayer compared to the midsection and outer canopies, even when applying conventional high volume sprays.

\section{ACKNOWLEDGEMENTS}

Thanks to Ron and Chris Bailey for use of their orchard. Aaron Waterman applied the sprays, and Kevin Steele and Mike Haslett of $P P C_{N Z}$ provided technical assistance.

\section{REFERENCES}

Hofstee, M.E.; Gaskin, R.E. 2003: Phytotoxicity of agrochemical adjuvants on avocados. N.Z. Plant Prot. 56: 274.

Gaskin, R.E.; Manktelow, D.W.; Elliott, G.S. 2002. New adjuvant technology for pesticide use on wine grapes. N.Z. Plant Prot. 55: 154-158.

Manktelow, D.W.; Gurnsey, S.J.; MacGregor, A.M. 2004: Deposit variability and prediction in fruit crops: What use are label rates anyway? In: International Advances in Pesticide Application. Aspects of Applied Biology 71: 269-278.

Murray, R.J.; Gaskin, R.E.; Grassam, M.R. 1998: Evaluation of a novel adjuvant for use with glyphosate on perennial ryegrass. N.Z. Plant Prot. 51: 162-165. 